\title{
AS AÇÕES DE COMUNICAÇÃO DOS AGENTES PÚBLICOS DURANTE O PERÍODO ELEITORAL: UMA ANÁLISE DO ACÓRDÃO TRESC N. 30.238, DE 27.10.2014
}

\author{
Hugo Frederico Vieira Neves
}

Resumo: A veiculação de publicidade institucional nos três meses que antecedem as eleições constitui conduta vedada aos agentes públicos durante a campanha, a teor do que prescreve a Lei n. 9.504, de 30 de setembro de 1997. De igual forma, a qualquer tempo e por prazo indeterminado, a veiculação de publicidade institucional em desalinho com os preceitos constitucionais da impessoalidade é regra proibitiva para os mesmos agentes públicos. De acordo com a Lei Eleitoral, o candidato beneficiado ficará sujeito à cassação do registro ou do diploma. Ocorre que as democracias contemporâneas não podem prescindir das liberdades de imprensa e de expressão - avanços civilizatórios incontestáveis -, ainda que seja durante o período de um pleito eleitoral. Como então conciliar a atividade jornalística em todos os seus matizes com as condutas proibidas em questão? Podem os profissionais da imprensa exercer plenamente a sua atividade de forma crítica durante o período de campanha eleitoral? E mais: deve a Administração Pública paralisar suas atividades e seu processo de comunicação com a sociedade nos períodos eleitorais em razão da existência destas regras restritivas? Como conciliar os preceitos da comunicação, da impessoalidade e da transparência sem incorrer em abusos de poder? Enfrentando esta questão, o Tribunal Regional Eleitoral de Santa Catarina definiu balizas e colocou sobre a balança da Justiça valores constitucionais como a liberdade de expressão e de imprensa, sem descuidar de sua missão igualmente constitucional de ser o guardião das Eleições em Santa Catarina. É o que se verá no presente artigo, no estudo de precedente lavrado no Acórdão n. 30.238, de 27.10.2014.

Palavras-chave: Publicidade institucional. Condutas vedadas. Abuso de poder. Liberdade de imprensa e de expressão. 


\section{Breve introdução e delimitação da matéria}

A Lei n. 9.504/1997, ao estabelecer normas gerais para as eleições, elencou em seu corpo normativo, dentre as condutas que são consideradas proibidas, a vedação para agentes públicos de autorizarem veiculação de propaganda institucional durante os três meses que antecedem o dia das eleições, ressalvadas as hipóteses legais e expressamente previstas.

Esta vedação está enunciada no art. 73, VI, "b" do mencionado diploma normativo, que possui esta redação:

Art. 73. São proibidas aos agentes públicos, servidores ou não, as seguintes condutas tendentes a afetar a igualdade de oportunidades entre candidatos nos pleitos eleitorais:

$[\ldots]$

VI - nos três meses que antecedem o pleito:

$[\ldots]$

b) com exceção da propaganda de produtos e serviços que tenham concorrência no mercado, autorizar publicidade institucional dos atos, programas, obras, serviços e campanhas dos órgãos públicos federais, estaduais ou municipais, ou das respectivas entidades da administração indireta, salvo em caso de grave e urgente necessidade pública, assim reconhecida pela Justiça Eleitoral.

$[\ldots]$

Efetivamente, conforme se extrai da letra da lei, o tipo proibido no art. 73, VI, "b”, Lei n. 9.504/97 diz respeito à autorização de publicidade institucional no período vedado.

Todavia, é importante salientar, desde logo, que a jurisprudência eleitoral pátria - em especial a do Tribunal Superior Eleitoral ${ }^{1}$ - entende que se enquadra no mencionado dispositivo, também, a veiculação (e não somente a autorização) de qualquer publicidade institucional nos 3 (três) meses que antecedem o pleito eleitoral, ressalvadas as exceções enunciadas no próprio dispositivo.

A seu turno, as exceções se dividem em duas: a) as autorizadas pela Justiça Eleitoral, desde que digam respeito a atos, programas, obras, serviços e campanhas em hipóteses de urgência e gravidade públicas; e b) as que se referem à propaganda de produtos e serviços que tenham concor-

\footnotetext{
${ }^{1}$ BRASIL, TSE. Recurso Especial Eleitoral n. 21.106. Relator Ministro Fernando Neves, DJ 01 de ago. de 2003.
} 
rência no mercado, classificadas como publicidade mercadológica a objetivar a projeção de vendas.

Outra forma de conduta vedada relacionada à comunicação dos agentes públicos está descrita no art. 74 do mencionado diploma legal e diz respeito a qualquer ação de comunicação institucional que possa configurar propaganda eleitoral, configurando-se abuso de autoridade, em manifesto desvio aos preceitos da impessoalidade estipulados no art. $37, \int 1^{\circ}$, da Constituição Federal, que preceitua que o ato de comunicação deve ser de caráter educativo, informativo ou de orientação social.

Neste contexto, importante destacar, as lições de Mateus Henrique de Carvalho $^{2}$ sobre a questão do abuso de poder e da violação do princípio da impessoalidade na propaganda institucional:

A Constituição Federal é intolerável ao uso de publicidades institucionais para promoção pessoal. Sempre que a legislação infraconstitucional refere-se à publicidade custeada pelo poder público, deve-se observar o artigo 37, caput, e seu parágrafo primeiro, da Carta Constitucional.

Vale destacar, ainda, que a proibição extraída deste dispositivo não está restrita a determinado período de campanha, mas em qualquer período anterior ao início do processo eleitoral. Nas palavras do autor antes mencionado, a conduta do art. 74 pode ser classificada como "conduta vedada com prazo indeterminado" 3 .

De igual forma, a norma restritiva deve ser interpretada de forma ampliativa no exato sentido de não permitir a violação dos pressupostos constitucionais por parte da Administração Pública.

Com efeito, o objetivo da delimitação dessas condutas - que configuram espécies do gênero abuso do poder político -, consiste em assegurar a igualdade de oportunidades entre candidatos e, por conseguinte, a normalidade, a lisura e a legitimidade das eleições, impedindo que agentes públicos favoreçam determinada candidatura, partido ou coligação concorrente.

${ }^{2}$ CARVALHO, Mateus Henrique de. As condutas vedadas de acordo com os artigos 73 a 78 da Lei 9.504/97 e seus aspectos processuais diante das ações de combate ao ilícito eleitoral. Porto Alegre: Verbo Jurídico, 2014, pág. 55.

${ }^{3}$ Idem, pág. 22.

Resenha Eleitoral (Florianópolis), v. 22, n. 1-2, p. 239-248, 2018 
Em verdade, as condutas vedadas são uma resposta do legislador ordinário ao instituto da reeleição - aprovado por emenda dez anos após a promulgação da Constituição Federal de 1988 -, uma vez que se revelava natural o temor em relação ao uso ilícito e abusivo da máquina estatal pelos agentes públicos que já ostentam a qualidade de detentores de mandatos eletivos, em especial os Chefes do Poder Executivo.

Logo, à toda evidência, as condutas vedadas dos dispositivos sob análise são espécies do gênero abuso de poder, praticadas por aqueles que necessariamente detêm o uso da máquina pública. Aliás, o emprego das engrenagens do Poder Público constitui a essência da regra de vedação à publicidade institucional.

Outras questões relevantes que circundam o tema das condutas vedadas relacionadas aos atos de comunicação dos agentes públicos dizem respeito à configuração da infração, da qual não se exige a prova de que a conduta tenha afetado o resultado do pleito, ou efetivamente beneficiado determinada candidatura ou, mesmo, prejudicado. Em outras palavras, a subsunção da norma ao fato independe de prova de prévio conhecimento do candidato eventualmente beneficiado.

Isto significa dizer que o proveito do Chefe do Poder Executivo (Prefeito, Governador ou Presidente) que esteja concorrendo à reeleição na hipótese de configuração das condutas vedadas em exame é evidente: a vedação à publicidade institucional é incondicional. A norma não determina que se investigue eventual benefício direto ao candidato à reeleição, pois ele é presumido pela própria Lei.

Por fim, antes de adentrar na análise jurisprudencial, é importante destacar que a publicidade legal - assim entendida aquela que objetiva a divulgação de balanços, atas, editais, decisões, avisos e meros atos administrativos do Poder Executivo -, não caracterizam publicidade institucional.

Registre-se, ainda, que na aplicação da penalidade é necessário considerar dados concretos para fins de individualização da pena e dosimetria, podendo incidir, além da cessação da veiculação da propaganda, a sanção de multa e cassação do diploma ou registro, a depender da proporcionalidade da reprimenda. 


\section{Análise jurisprudencial sobre as condutas vedadas do art. 73, VI, “b”, e art. 74, ambos da Lei n. 9.504/1997. Liberdade de imprensa como parâmetro a ser observado}

Enfrentando a matéria, o Tribunal Regional Eleitoral de Santa Catarina, por meio do Acórdão n. 30.238, de 27.10.2014, da lavra do Juiz Hélio do Valle Pereira ${ }^{4}$, se posicionou estabelecendo algumas premissas relacionadas ao tema.

Os contornos do exame recursal dizem respeito a 7 fatos, sendo que os 5 primeiros se relacionam às condutas vedadas do art. 73 , VI, "b" e do art. 74, ambos da Lei n. 9.504/1997, a saber: 1) publicação de matérias e nota oficial em jornais e sites que tratavam temas da Administração Pública Municipal; 2) postagem de notícia sobre verbas que seriam recebidas pela municipalidade; 3) veiculação de notícias sobre exonerações de servidores públicos municipais ligados a candidatos adversários; 4) divulgação pela assessoria de imprensa do município de matéria sobre a admissão de novos servidores; e 5) distribuição gratuita de jornais que publicaram os fatos 1 a 4 .

A petição inicial acusava a divulgação de notícias que teriam alegadamente caráter abusivo por parte da municipalidade, por parte de assessor de comunicação da Prefeitura formalmente afastado de seu cargo, através de veículos de imprensa, na modalidade jornais impressos e versão digital na internet.

Argumentava-se que os réus beneficiados, candidatos à reeleição da Chefia do Poder Executivo Municipal, haviam incorrido nas mencionadas condutas vedadas, bem como em abuso de poder político e econômico.

Aduziu-se, ainda, ter havido a distribuição gratuita de jornais locais com as matérias mencionadas configurando o ilícito abusivo.

A ação foi julgada improcedente na primeira instância e, em grau de recurso, o TRESC assim se pronunciou na ementa deste julgado:

RECURSO ELEITORAL - NOVAS ELEIÇÕES - AÇÃO DE INVESTIGAÇÃO JUDICIAL ELEITORAL - CONDUTA VEDADA E ABUSO DE PODER POLÍTICO E ECONÔMICO - REPORTAGENS JORNALÍSTICAS.

\footnotetext{
${ }^{4}$ Acórdão TRESC n. 30.238 de 27.10.2014, Relator o Juiz HÉLIO DO VALLE PEREIRA, Publicação: DJE - Diário de JE, tomo 194, Data 30.10.2014, pág. 8.

Resenha Eleitoral (Florianópolis), v. 22, n. 1-2, p. 239-248, 2018
} 
Eleições não paralisam o cotidiano administrativo ou a cobertura jornalística das coisas da Prefeitura. A disputa política não é uma extravagância, um período de exceção, assunto proibido. É claro que se pode, em tese, dissimular publicidade ilícita por meio de aparência de jornalismo, mas mesmo a exposição de opiniões favoráveis a uma candidatura ou acerbas a outras não representa em si uma conduta proibida, especialmente se não estiver revelada contribuição subjetiva da postulação beneficiada.

No caso concreto, inclusive, o que se afirma como indevido foram prosaicas reportagens sobre o dia a dia da municipalidade, nota oficial sem característica de propaganda e mesmo críticas pontuais radiofônicas e na imprensa escrita (em face das quais não se demonstrou nenhuma colaboração dos representados).

DISTRIBUIÇÃO GRATUITA DE JORNAIS JUSTAMENTE QUANTO A EDIÇÕES FAVORÁVEIS AOS RÉUS - FALTA DE PROVA - AUSÊNCIA DE VALOR DE DECLARAÇÕES APENAS VERTIDAS EM ESCRITURA PÚBLICA.

A distribuição gratuita de jornais, fato até então inexistente, poderia ter gravidade, mas não existe prova a esse respeito. Afirmações havidas em escritura pública provam a declaração, não a veracidade dos fatos subjacentes. Relato pessoal, para ter valor processual, deve ser feito em juízo, sob contraditório, mediante o procedimento da inquirição de testemunhas.

$[\ldots]$

NÃO RECONHECIMENTO DE CONDUTAS VEDADAS OU DE ABUSO DE PODER - DESPROVIMENTO DO RECURSO - MANUTENÇÃO DA SENTENÇA QUE JULGOU O PEDIDO IMPROCEDENTE.

No caso concreto, o Tribunal catarinense entendeu que as divulgações do jornalista - que exercia o cargo de assessor de comunicação, mas estava devidamente afastado de suas funções na municipalidade - estavam cobertas pela liberdade de imprensa e de expressão.

Destacou o relator do caso que seria "meramente conjectural" dizer que havia um atrelamento dos representados - os candidatos alegadamente beneficiados - com uma campanha publicitária relacionada à disputa político-eleitoral da época. 
Anotou-se que as notícias veiculadas retratavam o cotidiano administrativo e que, mesmo havendo eleições, o dia a dia da municipalidade deve prosseguir.

Com efeito, o que a Lei Eleitoral veda é a propaganda de caráter oficial (art. 73, VI, "b") ou a participação de candidatos detentores de mandato eletivo em atos de divulgação institucional (art. 74).

Não se está a proibir o registro de eventos da Administração Pública que, diga-se, também se pauta pelo princípio da publicidade e da transparência dos atos de gestão.

Por evidente, não escapou ao juízo do Tribunal a possibilidade de haver, em casos congêneres, a dissimulação de publicidade de caráter eleitoreiro sob o manto protetivo da atividade jornalística.

Todavia, ressaltou-se a posição jurisprudencial pacificada no sentido de que são admitidas no espectro da liberdade de imprensa até mesmo a exposição de opiniões jornalísticas favoráveis ou desfavoráveis a determinada candidatura, sem que isso constitua ilícito eleitoral.

Aliás, no que se refere às opiniões jornalísticas desfavoráveis, é bom que se diga que críticas jornalísticas são salutares numa democracia, ainda que em pleno período eleitoral, pois os mandatários não podem ser blindados contra discursos ásperos e posições inquisitivas.

Neste caminhar, não se pode partir da premissa de que os eleitores são tábulas rasas a formar opinião apenas pelo que de negativo se escreve sobre determinada candidatura; ao revés, prestigiar a liberdade de imprensa é reconhecer que alcançamos - eleitores e eleitos - maturidade democrática suficiente para conduzir um pleito sem desvios ou abusos.

De fato, não havendo a menção ao nome dos candidatos nem imagens ou ainda enaltecimento de feitos da Administração Pública e, numa hipótese mais absurda, pedido de voto direto ou indireto à determinada candidatura, não há falar no enquadramento das condutas vedadas dos arts. 73, VI, "b" e 74 da Lei das Eleições, porquanto ausentes contornos de condutas abusivas.

Finalmente, quanto à alegação de distribuição gratuita de jornais impressos na comunidade, o Tribunal entendeu que a mera declaração feita por escritura pública não era suficiente para provar o fato. 
Efetivamente, ausente prova robusta que pudesse evidenciar a conduta da qual se alegava abusividade de poder (econômico), as declarações firmadas em cartório por eleitores que diziam não serem assinantes dos periódicos não foram reconhecidas, por si só, como satisfatórias para determinar a dimensão dos fatos alegada pelos autores da representação, sendo a acusação julgada improcedente no ponto.

\section{Considerações finais}

À guisa de conclusão, tem-se que as condutas vedadas foram concebidas com o manifesto intuito de resguardar minimamente a igualdade de condições entre os concorrentes, o que foi acentuado com a implementação do instituto da reeleição dos Chefes do Poder Executivo.

Neste contexto, duas são as condutas proibidas aos agentes públicos no que se refere à comunicação de órgãos públicos: a) a primeira diz respeito à realização de ações publicitárias - chamada propaganda institucional - em desalinho com o que está previsto no art. 73, VI, "b", da Lei n. 9.504/1997; b) a segunda, refere-se a qualquer ação de comunicação oficial que possa configurar propaganda eleitoral e, por conseguinte, abuso de autoridade, consoante prevê o art. 74 do mesmo diploma legal.

Oportuno ressaltar que o reconhecimento da materialização das condutas vedadas aqui analisadas pode ter a grave consequência jurídica de cassar o registro ou o diploma do candidato implicado, consoante se extrai da parte final do art. 74 da Lei n. 9.504/1997. Desta penalidade, ainda pode decorrer a inelegibilidade por 8 anos prevista no art. 1ํ, I, “j”, da Lei Complementar n. 64/19905 , na hipótese de decisão condenatória transitada em julgado ou proferida por órgão colegiado.

Desta forma, além de robusto e incontroverso acervo probatório, cautela e prudência são indispensáveis no juízo de proporcionalidade dos casos levados à Justiça Eleitoral.

Com efeito, o precedente destacado revela que a Corte Eleitoral Catarinense - sem descurar de sua missão de coibir abusos e velar pela lisu-

\footnotetext{
${ }^{5}$ Art. 1ำ São inelegíveis: I - para qualquer cargo: j) os que forem condenados, em decisão transitada em julgado ou proferida por órgão colegiado da Justiça Eleitoral, por corrupção eleitoral, por captação ilícita de sufrágio, por doação, captação ou gastos ilícitos de recursos de campanha ou por conduta vedada aos agentes públicos em campanhas eleitorais que impliquem cassação do registro ou do diploma, pelo prazo de 8 (oito) anos a contar da eleição;
} 
ra das eleições, evitando o desequilíbrio entre os concorrentes - estabeleceu dois parâmetros fundamentais: a liberdade de expressão, como corolário da liberdade de imprensa e a não interferência no fluxo normal de atividades do poder público municipal, com o objetivo de não paralisar a máquina pública a serviço da sociedade durante o processo eleitoral.

Salutar, no ponto, reconhecer que o Tribunal Regional Eleitoral de Santa Catarina, ao se posicionar desta forma, conferiu maior relevo e prestígio às liberdades civis, bases de um Estado Democrático de Direito, o que em nada prejudica os atores do processo eleitoral nas atividades de controle, fiscalização e judicialização dos atos ilícitos praticados por agentes públicos durante a campanha eleitoral.

\section{Referências}

CARVALHO, Mateus Henrique de. As condutas vedadas de acordo com os artigos 73 a 78 da lei $\mathbf{9 . 5 0 4 / 9 7 ~ e ~ s e u s ~ a s p e c t o s ~ p r o c e s s u a i s ~ d i a n t e ~}$ das ações de combate ao ilícito eleitoral. Porto Alegre: Verbo Jurídico, 2014.

NIESS, Pedro Henrique Távora. Condutas vedadas aos agentes públicos em campanhas eleitorais: arts. 73 a 78 da Lei n. 9.504/97, reeleição, emenda constitucional n. 16/97. São Paulo: Edipro, 1998.

ZILIO, Rodrigo López. Direito Eleitoral. 3. ed. Porto Alegre: Verbo Jurídico, 2012.

Hugo Frederico Vieira Neves - Servidor público efetivo do Quadro Permanente do Tribunal Regional Eleitoral de Santa Catarina, Assessor Jurídico dos Juízes do Pleno; Bacharel em Direito pela Universidade do Vale do Itajaí; Licenciado em Letras pela Universidade Federal de Santa Catarina; Pós-graduado em Direito do Estado pela Universidade Anhanguera; Professor autônomo de Direito Eleitoral na Pós-graduação da Universidade do Vale do Itajaí; Palestrante e conferencista de Direito Eleitoral; foi Vice-Diretor da Escola Judiciária Eleitoral de Santa Catarina e atualmente é Membro Efetivo do Instituto dos Advogados de Santa Catarina. 
